\title{
Single-Valued DMBE Potential Energy Surface for HSO: A Distributed $n$-Body Polynomial Approach
}

\author{
E. Martínez-Núñez and A. J. C. Varandas* \\ Departamento de Química, Universidade de Coimbra, P-3049 Coimbra, Portugal
}

Received: January 11, 2001; In Final Form: March 27, 2001

\begin{abstract}
An accurate single-valued double many-body expansion (DMBE) potential energy surface is reported for the ground electronic state of HSO based on novel MR CISD ab initio energies suitably corrected for the complete one-electron basis set/complete CI limit. To improve the accuracy of the fit, we have suggested a $n$-body distributed polynomial approach which implies using individual multinomial developments at the various stationary points. For simplicity, only the three most relevant such points have been considered: two minima (HSO, HOS) and the saddle point connecting them.
\end{abstract}

\section{Introduction}

The chemistry of atmospheric sulfur is of great interest due to its importance in environmental issues. In particular, a considerable number of experimental studies have been reported for the $\mathrm{O}\left({ }^{3} P\right)+\mathrm{H}_{2} \mathrm{~S}$ system. ${ }^{1-6}$ Goumri et al. ${ }^{7}$ studied the geometrical features and energetics for the minima and 11 transition states of this system at the MP2 $=$ FULL/6-31G(d) and Gaussian-2 (G-2) levels of theory. They have also calculated canonical transition state theory rate coefficients for the various channels arising from the $\mathrm{O}\left({ }^{3} P\right)+\mathrm{H}_{2} \mathrm{~S}$ reaction and compared with experiment. For a complete analysis of the experimental results, a classical and/or quantum dynamics study would therefore be desirable. For this purpose, one requires to construct a global potential energy surface for the $\mathrm{H}_{2} \mathrm{OS}$ system. As a first step in this construction, potential energy surfaces surfaces must be provided for the various fragments. Among them is HSO, which is an important molecule per se in atmospheric chemistry. In particular, it may be involved in a so-called catalytic cycle ${ }^{8-10}$ for destruction of ozone in the troposphere, namely

$$
\begin{gathered}
\mathrm{HS}+\mathrm{O}_{3} \rightarrow \mathrm{HSO}+\mathrm{O}_{2} \\
\mathrm{HSO}+\mathrm{O}_{3} \rightarrow \mathrm{HS}+2 \mathrm{O}_{2}
\end{gathered}
$$

There have been numerous experimental and theoretical studies of the HSO and HOS isomers. ${ }^{11-28} \mathrm{Ab}$ initio calculations for the HSO and HOS radicals were first reported by Sannigrahi et al., ${ }^{26}$ who predicted HOS to be more stable than HSO. Several ab initio calculations ${ }^{7}$ have been reported afterward which corroborated such a prediction, although the magnitude of the energy difference between the minima associated with these species was found to decrease with improvement in the quality of the calculations. In fact, it was pointed out by Xantheas and Dunning ${ }^{27}$ that failure to account for dynamical correlation and the inadequacy of the basis sets were the main reasons why earlier calculations led to poor geometries and failed to correctly predict the relative stability of HSO and HOS. It seems well-established ${ }^{7}$ now that HSO is more stable than HOS. However, most ab initio calculations so far reported have been devoted to studying the minima and the transition state for the isomerization process. An exception is the work by Xantheas and Dunning, ${ }^{27}$ who have computed the minimum energy paths for the addition of $\mathrm{H}$ to $\mathrm{SO}$ to form HSO and HOS. In the present work, we report novel full valence complete active space (FVCAS) and multireference configuration interaction (MRCI) calculations covering over 500 geometries, including the minima, transition states, and $\mathrm{S}-\mathrm{H}-\mathrm{O}$ geometries. Moreover, we have subsequently corrected the calculated ab initio energies by means of the double manybody expansion-scaled external correlation (DMBE-SEC) method $^{29}$ to account for the complete basis set/complete CI limits. The resulting DMBE-SEC energies have then been used to calibrate a potential energy surface based on the $\mathrm{DMBE}^{30-33}$ formalism (see also ref 34 ). This potential energy surface shows the correct long-range behavior at all dissociation channels and provides a realistic representation at all interatomic separations, especially those covered by the calculated ab initio energies.

The paper is organized as follows. Section 2 describes the ab initio calculations carried out in the present work. In section 3 , we deal with the representation of the DMBE potential energy surface. Specifically, section 3.1 focuses on the two-body energy terms, while section 3.2 concentrates on the three-body energy terms. The main topographical features of the DMBE potential energy surface are discussed in section 4. Some concluding remarks are in section 5 .

\section{Ab Initio Calculations}

The ab initio calculations have been carried out at the $\mathrm{MRCI}^{35}$ level with a FVCAS ${ }^{36,37}$ as the reference wave function. For the basis set, we have selected the aug-cc-pvtz (AVTZ) of Dunning, ${ }^{38-40}$ with the calculations being carried out using the MOLPRO $^{41}$ package. A total of 500 grid points have been chosen to map the potential energy surface over the region defined by $2.61 \leq r / a_{0} \leq 8.76,1.91 \leq R / a_{0} \leq 6.73$, and $0 \leq$ $\gamma /$ deg $\leq 180$. The Jacobi coordinates $r, \mathbf{R}$, and $\gamma$ are defined in Figure 1: $r$ is the SO distance, $\mathbf{R}$ is the vector associated with the atom-diatom separation connecting the $\mathrm{H}$ atom to the geometrical center of SO, and $\gamma$ is defined by $\cos \gamma=r \mathbf{R} /|r \mathbf{R}|$. We have also studied at the same level of theory the complicated potential energy curves for $\mathrm{SO}, \mathrm{SH}$, and $\mathrm{OH}$ (78 points in all). The ab initio energies determined in this way were subsequently corrected by using the DMBE-SEC method ${ }^{32}$ to account for the excitations beyond singles and doubles and, more importantly, for the incompleteness of the one-electron basis set. 


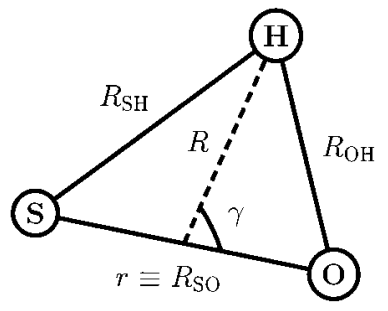

Figure 1. Coordinate system used in the present work.

In the DMBE-SEC method, the total interaction energy of the triatomic is written as ${ }^{29}$

$$
V(\mathbf{R})=V_{\mathrm{FVCAS}}(\mathbf{R})+V_{\mathrm{DMBE}-\mathrm{SEC}}(\mathbf{R})
$$

where

$$
V_{\mathrm{FVCAS}}(\mathbf{R})=\sum_{\mathrm{AB}} V_{\mathrm{AB}, \mathrm{FVCAS}}^{(2)}\left(R_{\mathrm{AB}}\right)+V_{\mathrm{ABC}, \mathrm{FVCAS}}^{(3)}\left(R_{\mathrm{AB}}, R_{\mathrm{BC}}, R_{\mathrm{AC}}\right)
$$$$
V_{\mathrm{DMBE}-\mathrm{SEC}}(\mathbf{R})=\sum_{\mathrm{AB}} V_{\mathrm{AB}, \mathrm{DMBE}-\mathrm{SEC}}^{(2)}\left(R_{\mathrm{AB}}\right)+
$$

$$
V_{\mathrm{ABC}, \mathrm{DMBE}-\mathrm{SEC}}^{(3)}\left(R_{\mathrm{AB}}, R_{\mathrm{BC}} R_{\mathrm{AC}}\right)
$$

and the summations extend to all diatomic fragments. In turn, the three-body energy term of the SEC series expansion assumes the form

$$
\begin{aligned}
& V_{\mathrm{AB}, \mathrm{DMBE}-\mathrm{SEC}}^{(2)}\left(R_{\mathrm{AB}}\right)=\left[V_{\mathrm{AB}, \mathrm{FVCAS}-\mathrm{CISD}}^{(2)}\left(R_{\mathrm{AB}}\right)\right. \\
&\left.-V_{\mathrm{AB}, \mathrm{FVCAS}}^{(2)}\left(R_{\mathrm{AB}}\right)\right] / F_{\mathrm{AB}}^{(2)} \\
& V_{\mathrm{ABC}, \mathrm{DMBE}-\mathrm{SEC}}^{(3)}\left(R_{\mathrm{AB}}, R_{\mathrm{BC}}, R_{\mathrm{AC}}\right)= \\
& {\left[V_{\mathrm{ABC}, \mathrm{FVCAS}-\mathrm{CISD}}^{(3)}\left(R_{\mathrm{AB}}, R_{\mathrm{BC}}, R_{\mathrm{AC}}\right)-\right.} \\
&\left.V_{\mathrm{ABC}, \mathrm{FVCAS}}^{(3)}\left(R_{\mathrm{AB}}, R_{\mathrm{BC}}, R_{\mathrm{AC}}\right)\right] / F_{\mathrm{ABC}}^{(3)}
\end{aligned}
$$

where $F_{\mathrm{AB}}^{(2)}$ is a parameter being chosen to reproduce the bond dissociation energy of the corresponding $\mathrm{AB}$ diatomic. Because of the lack of similar spectroscopic information on the welldepth of the triatomic, the corresponding three-body factor $F_{\mathrm{ABC}}^{(3)}$ has been taken as the average of the two-body $F$-factors. Such a procedure, originally tested ${ }^{29}$ on ground-state $\mathrm{HO}_{2}$, led in the present case to the values $F_{\mathrm{SO}}^{(2)}=0.6850, F_{\mathrm{SH}}^{(2)}=0.7713$, $F_{\mathrm{OH}}^{(2)}=0.7826$, and $F_{\mathrm{HSO}}^{(3)}=0.7463$.

\section{DMBE Potential Energy Surface for HSO}

3.1. Two-Body Energy Terms. The diatomic potential energy curves have been modeled using the extended HartreeFock approximation correlation energy method for diatomics, including the united atom limit (EHFACE2U), ${ }^{42}$ with the available parameters being determined by fitting experimental and $\mathrm{ab}$ initio data. They assume the general form ${ }^{31,42}$

$$
V(R)=V_{\mathrm{EHF}}+V_{\mathrm{dc}}
$$

where EHF refers to the extended Hartree-Fock type energy and dc is the dynamical correlation energy. As usual, the latter is modeled semiempirically by ${ }^{43}$

$$
V_{\mathrm{dc}}(R)=-\sum_{n=6,8,10} \chi_{n}(R) \frac{C_{n}}{R^{n}}
$$

with the damping functions for the dispersion coefficients

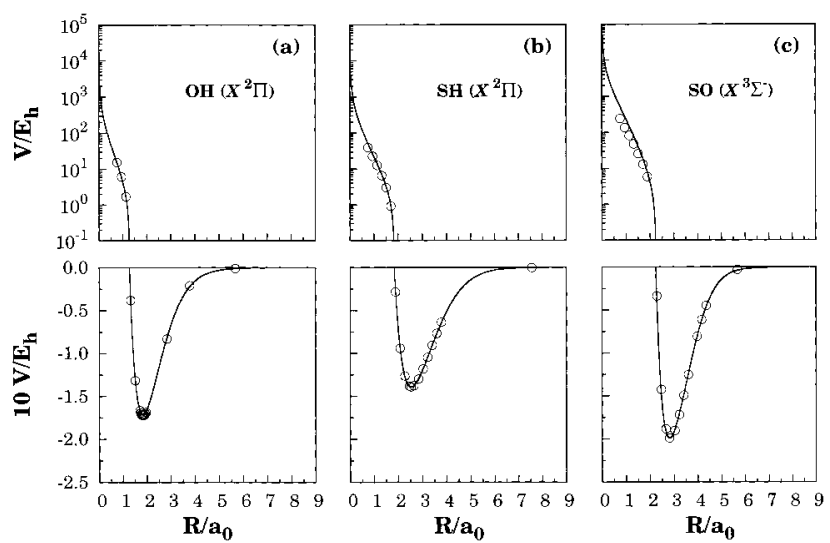

Figure 2. EHFACE2U potential energy curves: (a) $\mathrm{OH}\left(\mathrm{X}^{2} \Pi\right)$, (b) $\mathrm{SH}\left(\mathrm{X}^{2} \Pi\right)$, and (c) $\mathrm{SO}\left(\mathrm{X}^{3} \Sigma^{-}\right)$. The circles indicate the ab initio points and the lines the EHFACE2U values.

assuming the form

$$
\chi_{n}(R)=\left[1-\exp \left(-A_{n} \frac{R}{\rho}-B_{n} \frac{R^{2}}{\rho^{2}}\right)\right]^{n}
$$

In eq $10, A_{n}$ and $B_{n}$ are auxiliary functions defined by

$$
\begin{gathered}
A_{n}=\alpha_{0} n^{-\alpha_{1}} \\
B_{\mathrm{n}}=\beta_{0} \exp \left(-\beta_{1} n\right)
\end{gathered}
$$

where $\alpha_{0}, b_{0}, \alpha_{1}$, and $\beta_{1}$ are universal dimensionless parameters for all isotropic interactions ${ }^{30,31} \alpha_{0}=16.36606, \alpha_{1}=0.70172$, $b_{0}=17.19338$, and $\beta_{1}=0.09574$. Moreover, the scaling parameter $\rho$ is defined as

$$
\rho=5.5+1.25 R_{0}
$$

where $R_{0}=2\left(\left\langle r_{\mathrm{X}}^{2}\right\rangle^{1 / 2}+\left\langle r_{\mathrm{Y}}^{2}\right\rangle^{1 / 2}\right)$ is the LeRoy ${ }^{44}$ distance for onset of the undamped $R^{-n}$ series expansion and $\left\langle r_{X}^{2}\right\rangle$ is the expectation value of the squared radius for the outermost electrons of atom X (similarly for atom Y). Finally, the exponentially decaying part of the EHF-type energy term is represented by the general form

$$
V_{\mathrm{EHF}}(R)=-\frac{D}{R}\left(1+\sum_{i=1}^{3} a_{i} r^{i}\right) \exp (-\gamma r)
$$

where

$$
\gamma=\gamma_{0}\left[1+\gamma_{1} \tanh \left(\gamma_{2} r\right)\right]
$$

where $r=R-R_{\mathrm{e}}$ is the displacement coordinate from the equilibrium diatomic geometry; $D, a_{i}(i=1 \rightarrow 3)$, and $\gamma_{i}(i=$ $0 \rightarrow 2$ ) are adjustable parameters to be obtained as described elsewhere. ${ }^{31,42}$

For the ground-state hydroxyl radical $\mathrm{OH}\left(\mathrm{X}^{2} \Pi\right)$, we have used a potential energy curve previously reported by one of us and Voronin ${ }^{45}$ which has been calibrated using Rydberg-KleinRees (RKR)-type data. Figure 2a shows that the potential energy function so obtained also reproduces our calculated ab initio energies.

For the sulfur hydride ground state, $\mathrm{SH}\left(\mathrm{X}^{2} \Pi\right)$, there is no RKR experimental data, and hence, we have used our own ab initio points and the experimental dissociation energy ${ }^{46}$ in the 
TABLE 1: Long-Range Coefficients for the Diatomic Fragments in au

\begin{tabular}{lccrr}
\hline & $R_{0}$ & $C_{6}$ & \multicolumn{1}{c}{$C_{8}$} & \multicolumn{1}{c}{$C_{10}$} \\
\hline $\mathrm{SO}\left(X^{3} \Sigma^{-}\right)$ & 7.3119 & 53.09 & 1206.5 & 30982.5 \\
$\mathrm{SH}\left(X^{2} \Pi\right)$ & 7.9652 & 34.49 & 896.5 & 26332.1 \\
$\mathrm{OH}\left(X^{2} \Pi\right)$ & 6.2949 & 11.47 & 195.0 & 4342.3
\end{tabular}

TABLE 2: Parameters of the Two-Body Hartree-Fock Energy in au

\begin{tabular}{llll}
\hline & $\mathrm{SO}\left(X^{3} \Sigma^{-}\right)$ & $\mathrm{SH}\left(X^{2} \Pi\right)$ & $\mathrm{OH}\left(X^{2} \Pi\right)$ \\
\hline$R_{\mathrm{e}}$ & 2.7988 & 2.5334 & 1.8344 \\
$D$ & 0.479589 & 0.308372 & 0.275865 \\
$a_{1}$ & 2.2594 & 1.8997 & 2.2904 \\
$a_{2}$ & 1.2128 & 0.7234 & 1.0466 \\
$a_{3}$ & 1.0265 & 0.2562 & 0.5147 \\
$\gamma_{0}$ & 1.7823 & 1.4139 & 1.7110 \\
$\gamma_{1}$ & 3.6305 & 6.3459 & 1.9222 \\
$\gamma_{2}$ & 0.0458 & 0.0146 & 0.0747
\end{tabular}

TABLE 3: Numerical Values, in au, of the Parameters in Eq 19

\begin{tabular}{cccc}
\hline $\mathrm{S}-\mathrm{OH}$ & $C_{6}(R)$ & $C_{8}(R)$ & $C_{10}(R)$ \\
\hline$R_{\mathrm{M}}$ & 4.0 & 4.0 & 4.0 \\
$D_{\mathrm{M}}$ & 34.28 & 1044.0 & 34824.0 \\
$a_{1}$ & -0.0150 & -0.0751 & -0.0987 \\
$a_{2}$ & -0.2371 & -0.2452 & -0.2481 \\
$a_{3}$ & 0.0860 & 0.1014 & 0.1073 \\
$b_{2}$ & 0.1532 & 0.1696 & 0.1799 \\
$b_{3}$ & 0.0068 & 0.0122 & 0.0137 \\
\hline $\mathrm{O}-\mathrm{SH}$ & $C_{6}(R)$ & $C_{8}(R)$ & $C_{10}(R)$ \\
\hline$R_{\mathrm{M}}$ & 4.94 & 4.93 & 4.92 \\
$D_{\mathrm{M}}$ & 17.13 & 537.2 & 17643.0 \\
$a_{1}$ & -0.1269 & -0.1603 & -0.1842 \\
$a_{2}$ & -0.1776 & -0.1712 & -0.1677 \\
$a_{3}$ & 0.0863 & 0.0879 & 0.0903 \\
$b_{2}$ & 0.1741 & 0.1830 & 0.1919 \\
$b_{3}$ & 0.0188 & 0.0203 & 0.0216 \\
\hline $\mathrm{H}_{-} \mathrm{SO}$ & $C_{6}(R)$ & $C_{8}(R)$ & $C_{10}(R)$ \\
\hline$R_{\mathrm{M}}$ & 5.29 & 5.41 & 5.49 \\
$D_{\mathrm{M}}$ & 16.20 & 457.7 & 14495.0 \\
$a_{1}$ & 0.7627 & 0.7699 & 0.7739 \\
$a_{2}$ & 0.1331 & 0.1238 & 0.1177 \\
$a_{3}$ & 0.0009 & 0.0006 & 0.0012 \\
$b_{2}$ & 0.0784 & 0.1018 & 0.1219 \\
$b_{3}$ & $1.0 \times 10^{-6}$ & 0.0009 & 0.0006 \\
& & &
\end{tabular}

fitting procedure. Figure $2 \mathrm{~b}$ shows that the model potential accurately reproduces the ab initio energies while showing good ability for extrapolation to the regions not covered by the fitted data. The sulfur oxide ground-state $\mathrm{SO}\left(\mathrm{X}^{3} \Sigma^{-}\right)$potential energy curve has been calibrated by fitting our FVCAS-SEC energies and the experimental RKR points of Singh et al. ${ }^{47}$ in conjunction with the recent heat of formation determined by Clerbaux et al. ${ }^{48}$ Except for the last inner ab initio points, Figure $2 \mathrm{c}$ shows that the data is represented quite reliably. However, at very short distances, the ab initio points may not be as accurate, while the EHFACE2U model leads by construction to the proper unitedatom limit of the collapsed diatomic $(R \rightarrow 0)$. The numerical values of all diatomic parameters are gathered in Table 1 and Table 2.

3.2. Three-Body Energy Terms. Following the usual procedure $^{30-33}$ (see also ref 34), we split the three-body energy into several contributions. Specifically, one has the extended Hartree-Fock and dynamical correlation parts, with the electrostatic component of the EHF part also considered independently. In the following subsections, we provide a description of each component. To represent the three-body dynamical

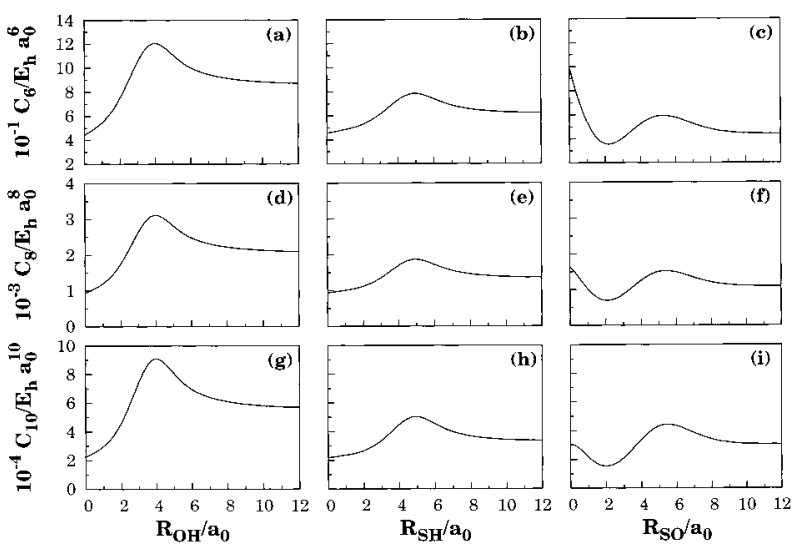

Figure 3. Dispersion coefficients for the atom-diatom asymptotic channels of HSO as a function of the corresponding intramolecular distance. The $C_{6}$ coefficients are displayed in panels a for $\mathrm{S}-\mathrm{OH}, \mathrm{b}$ for $\mathrm{O}-\mathrm{SH}$ and $\mathrm{c}$ for $\mathrm{H}-\mathrm{SO}$. Panels $\mathrm{d}-\mathrm{f}$ show the corresponding $C_{8}$ coefficients and $\mathrm{g}-\mathrm{i}$ those of $C_{10}$.

correlation and the electrostatic energies, we have chosen the general form proposed by one of authors, ${ }^{49}$ namely

$$
V_{\mathrm{dc}, \mathrm{ele}}^{(3)}=\sum_{i} \sum_{n} f_{i}(\mathbf{R}) C_{n}^{(i)}\left(R_{i}, \theta_{i}\right) \chi_{n}\left(r_{i}\right) r_{i}^{-n}
$$

where $i$ labels the $\mathrm{I}-\mathrm{JK}$ channel associated with the center of mass separation $r_{i}, R_{i}$ is the $\mathrm{J}-\mathrm{K}$ bond distance, and $\cos \theta_{i}=$ $\vec{r}_{i} \vec{R}_{i} /\left|\vec{r}_{i} \vec{R}_{i}\right|$; for the notation, see Figure 1 of ref 32 . In turn, $C_{n}^{(i)}\left(R_{i}, \theta_{i}\right)$ are electrostatic coefficients when $n=4$ or 5 , representing the dipole-quadrupole and quadrupole-quadrupole interactions. For $n=6,8$, and $10, C_{n}^{(i)}\left(R_{i}, \theta_{i}\right)$ 's represent atomdiatom dispersion coefficients given by

$$
C_{n}^{(i)}=\sum_{L} C_{n}^{\mathrm{L}} P_{\mathrm{L}}\left(\cos \theta_{i}\right)
$$

where $P_{\mathrm{L}}\left(\cos \theta_{i}\right)$ denotes the L-th term of the Legendre polynomial expansion and $C_{n}^{\mathrm{L}}$ is the associated expansion coefficient. Additionally, the function $\chi_{n}\left(r_{i}\right)$ in eq 16 is the corresponding diatomic damping function given by eq 10 . Moreover, $f_{i}(\mathbf{R})$ is a switching function chosen from the requirement that it must be +1 for $R_{i}=R_{i}^{\mathrm{e}}$ and $r_{i} \rightarrow \infty$ and 0 for $R_{i} \rightarrow \infty$. Following previous work, ${ }^{49}$ we have employed the form

$$
f_{i}=\frac{1}{2}\left\{1-\tanh \left[\xi\left(\eta s_{i}-s_{j}-s_{k}\right)\right]\right\}
$$

where $s_{i}=R_{i}-R_{i}^{\mathrm{e}}$ (corresponding expressions apply for $s_{j}, s_{k}$, $f_{k}$, and $f_{k}$ ), and $\eta$ is a constant chosen to ensure the proper asymptotic behavior; as before, ${ }^{49}$ we have chosen the value $\eta$ $=3$ such as to satisfy the proper asymptotic limits. Furthermore, the parameter $\xi$ has been taken as the average of the exponents of the $\mathrm{OH}$ and $\mathrm{SH}$ range decaying factors in the three-body term: $\xi=0.58 a_{0}^{-1}$. Regarding the damping functions $\chi_{n}\left(r_{i}\right)$, we still adopt eq 10 but replace $R$ by the center-of-mass separation for the relevant atom-diatom channel. Additionally, the value of $\rho$ has been assumed as the average value of the corresponding $\mathrm{OH}$ and $\mathrm{SH}$ diatomic scaling parameters. Finally, $r_{i}$ has been approximated ${ }^{31}$ by $r_{i}=\left(R_{j}+R_{k}\right) / 2$.

3.2.1. Three-Body Dynamical Correlation Energy. Following previous work, ${ }^{49}$ only the spherically averaged components $(L$ $=0$ ) of the atom-diatom dispersion coefficients have been considered, with the involved internuclear dependences being 

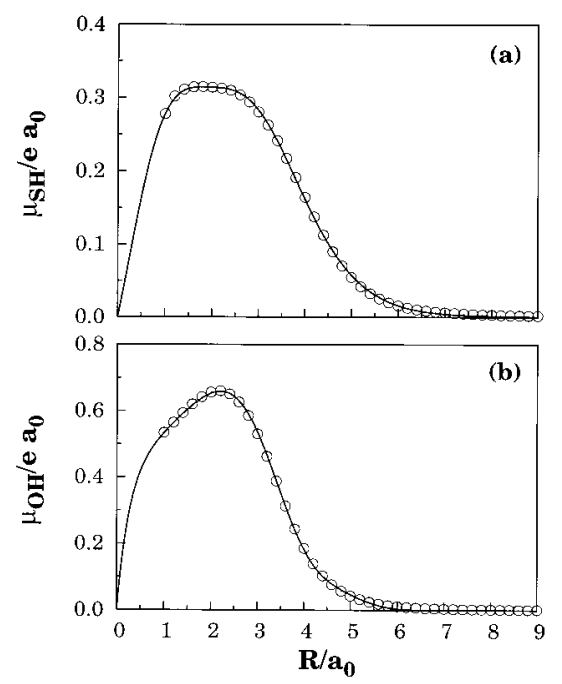

Figure 4. Variation of the $\mathrm{OH}$ (a) and $\mathrm{SH}$ (b) dipole moments with internuclear distance. Circles indicate MR-CISD points, while the lines indicate the results predicted from eq 22 .

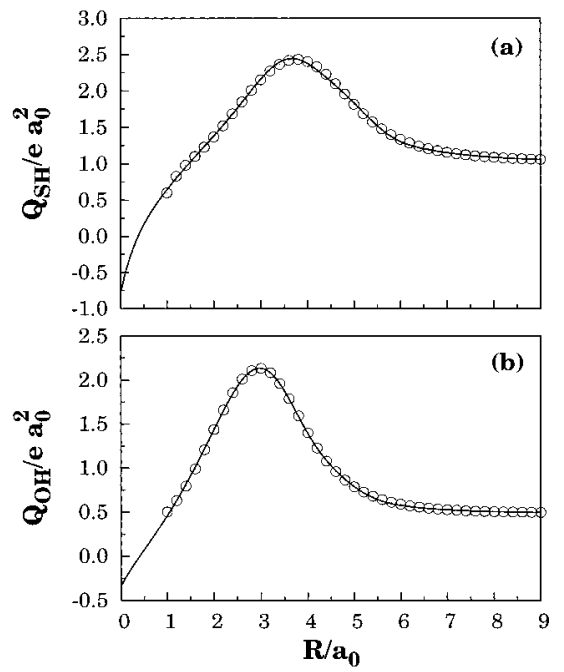

Figure 5. Variation of the $\mathrm{OH}$ (a) and $\mathrm{SH}$ (b) quadrupole moments with internuclear distance. Circles indicate the MR-CISD points, while the lines show the results predicted from eq 23.

estimated as reported elsewhere, ${ }^{50}$ i.e., by using the dipolar isotropic polarizabilities (calculated in this work at the MRCI level of theory), combined with a generalized Slater-Kirkwood approximation. ${ }^{51}$ The atom-diatom dispersion coefficients were then fitted to the form

$$
C_{n}^{\mathrm{A}-\mathrm{BC}}(R)=C_{n}^{\mathrm{AB}}+C_{n}^{\mathrm{AC}}+D_{\mathrm{M}}\left(1+\sum_{i=1}^{3} a_{i} r^{i}\right) \exp \left(-\sum_{i=1}^{3} b_{i} r^{i}\right)
$$

where $r=R-R_{\mathrm{M}}$ is the displacement relative to the position of the maximum and $b_{1} \equiv a_{1}$. The parameters that resulted from the fits are reported in Table 3 , and the internuclear dependences of the dispersion coefficients are shown in Figure 3.

As pointed out elsewhere, ${ }^{49}$ eq 16 causes an overestimation of the dynamical correlation energy at the atom-diatom dissociation channel. To correct such a behavior, we have multiplied the two-body dynamical correlation energy for the $i$-th pair by $f_{i}(\mathbf{R})$ and, correspondingly, for the channels $j$ and $k$. This ensures ${ }^{49}$ that the only two-body contribution at the $i$-th channel is that of $\mathrm{JK}$.

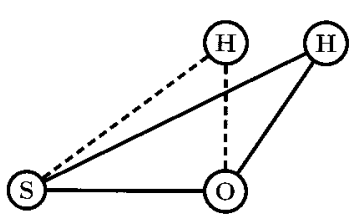

(a)

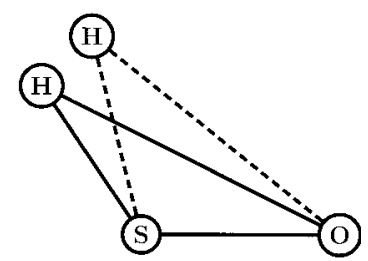

(b)

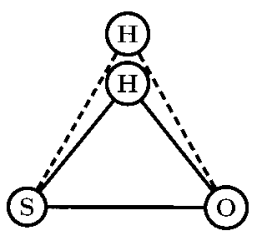

(c)

Figure 6. Reference geometries used in the present work for the threebody EHF part of the potential energy surface: (a) HOS, (b) HSO, and (c) transition state for reaction HSO $\rightarrow$ HOS. The solid lines represent the equilibrium geometries of the corresponding stationary points, while the dotted lines show the reference geometries which have been actually employed.

TABLE 4: Numerical Values, in au, for $\mathrm{OH}$ and SH Dipole Moments in Eq 22

\begin{tabular}{lcc}
\hline & $\mathrm{OH}$ & $\mathrm{SH}$ \\
\hline$R_{\mathrm{M}}$ & 2.20 & 1.8 \\
$D_{\mathrm{M}}$ & 0.658585 & 0.314426 \\
$a_{1}$ & -0.29843 & 0.189345 \\
$a_{2}$ & -0.174482 & -0.165016 \\
$a_{3}$ & 0.0762564 & 0.0174276 \\
$b_{2}$ & 0.0204867 & 0.0134371 \\
$b_{3}$ & 0.1171210 & 0.000001
\end{tabular}

TABLE 5: Numerical Values, in au, for $\mathrm{OH}$ and $\mathrm{SH}$ Quadrupole Moments in Eq 23

\begin{tabular}{lcc}
\hline & $\mathrm{OH}$ & $\mathrm{SH}$ \\
\hline$R_{\mathrm{M}}$ & 3.0 & 3.7 \\
$M_{6}$ & 5500 & 21000 \\
$D_{\mathrm{M}}$ & 1.127 & 0.65607488 \\
$a_{1}$ & -0.314458 & 0.01782770 \\
$a_{2}$ & -0.254650 & -0.1186250 \\
$a_{3}$ & 0.2301120 & 0.54471800 \\
$b_{1}$ & -0.373896 & -0.0758723 \\
$b_{2}$ & 0.5226040 & 0.70193800 \\
$b_{3}$ & 0.1344000 & 0.14595400 \\
$Q_{\infty}$ & 0.49 & 1.05
\end{tabular}

3.2.2. Three-Body Electrostatic Energy. Since the $\mathrm{H}$ atom has spherical symmetry, we have to consider only the interactions of the oxygen and sulfur quadrupoles with the $\mathrm{SH}$ and $\mathrm{OH}$ dipole and quadrupolar moments. Thus, a total of four electrostatic interactions have been taken into account. As stated above, eq 16 has been employed to write the electrostatic energy, and in this case, $C_{n}\left(R_{i}, \theta_{i}\right)$ 's are electrostatic coefficients. If the Buckingham convention is used, ${ }^{52}$ such coefficients assume the form

$$
\begin{aligned}
& C_{4, \mathrm{ele}}\left(R_{\mathrm{AB}}, \theta\right)=\frac{3}{2} \mu_{\mathrm{AB}} Q_{\mathrm{C}} A_{\mathrm{DQ}}\left(\theta_{a}, \theta_{b}, \phi_{a b}\right) \\
& C_{5, \text { ele }}\left(R_{\mathrm{AB}}, \theta\right)=\frac{3}{4} Q_{\mathrm{AB}} Q_{\mathrm{C}} A_{\mathrm{QQ}}\left(\theta_{a}, \theta_{b}, \phi_{a b}\right)
\end{aligned}
$$

where the indexes $\mathrm{AB}$ and $\mathrm{C}$ stand for $\mathrm{OH}(\mathrm{SH})$ and $\mathrm{S}$ (or $\mathrm{O})$, respectively. The functional forms of $A_{\mathrm{DQ}}$ and $A_{\mathrm{QQ}}$ were those employed in previous work ${ }^{53}$ based on the so-called classical optimized quadrupole ${ }^{54}$ model, according to which the 
TABLE 6: Numerical Values of the Coefficients of Polynomial A in the Three-Body Extended Hartree-Fock Energy in au

\begin{tabular}{|c|c|c|}
\hline $\begin{array}{c}\gamma_{1}^{\mathrm{A}}=0.85 \\
R_{1}^{\mathrm{A}, \mathrm{ref}}=3.30\end{array}$ & $\begin{array}{c}\gamma_{2}^{A}=0.58 \\
R_{2}^{A, \text { ref }}=3.56\end{array}$ & $\begin{array}{c}\gamma_{3}^{\mathrm{A}}=0.49 \\
R_{3}^{\mathrm{A}, \mathrm{ref}}=1.73\end{array}$ \\
\hline $\begin{array}{l}c_{000}^{\mathrm{A}}=-0.152971042 \\
c_{003}^{\mathrm{A}}=0.410335814 \\
c_{010}^{\mathrm{A}}=-0.0318850512 \\
c_{013}^{\mathrm{A}}=0.196064485 \\
c_{021}^{\mathrm{A}}=-0.841754198 \\
c_{030}^{\mathrm{A}}=-0.23207117 \\
c_{040}^{\mathrm{A}}=0.10834947 \\
c_{100}^{\mathrm{A}}=-0.160730172 \\
c_{103}^{\mathrm{A}}=0.221896139 \\
c_{111}^{\mathrm{A}}=-0.0399540713 \\
c_{120}^{\mathrm{A}}=0.250767376 \\
c_{130}^{\mathrm{A}}=-0.200739683 \\
c_{200}^{\mathrm{A}}=0.231212503 \\
c_{203}^{\mathrm{A}}=-0.00488797525 \\
c_{212}^{\mathrm{A}}=-0.255883112 \\
c_{230}^{\mathrm{A}}=0.265091203 \\
c_{302}^{\mathrm{A}}=0.0481590732 \\
c_{320}^{\mathrm{A}}=0.279140359 \\
c_{410}^{\mathrm{A}}=-0.0497157716\end{array}$ & $\begin{aligned} c_{001}^{A} & =-0.0106451758 \\
c_{004}^{A} & =-0.0186074137 \\
c_{011}^{A} & =0.0773253466 \\
c_{014}^{A} & =-0.0801457935 \\
c_{022}^{A} & =0.241822527 \\
c_{031}^{A} & =-0.495856539 \\
c_{041}^{A} & =0.0439618526 \\
c_{101}^{A} & =-0.145518002 \\
c_{104}^{A} & =0.0335980733 \\
c_{112}^{A} & =0.54277435 \\
c_{121}^{A} & =-0.0443403774 \\
c_{131}^{A} & =-0.148990628 \\
c_{201}^{A} & =-0.571911856 \\
c_{210}^{A} & =-0.612887845 \\
c_{220}^{A} & =-0.0467274605 \\
c_{300}^{A} & =-0.947014418 \\
c_{310}^{A} & =0.441634224 \\
c_{400}^{A} & =0.368292954 \\
c_{500}^{A} & =0.0184014022\end{aligned}$ & $\begin{array}{l}c_{002}^{\mathrm{A}}=0.02841603 \\
c_{005}^{\mathrm{A}}=0.0243697848 \\
c_{012}^{\mathrm{A}}=0.352135922 \\
c_{020}^{\mathrm{A}}=0.328257694 \\
c_{023}^{\mathrm{A}}=0.135119134 \\
c_{032}^{\mathrm{A}}=-0.101029651 \\
c_{050}^{\mathrm{A}}=0.0777769216 \\
c_{102}^{\mathrm{A}}=0.708973954 \\
c_{110}^{\mathrm{A}}=-0.368934267 \\
c_{113}^{\mathrm{A}}=-0.0953548204 \\
c_{122}^{\mathrm{A}}=0.423678731 \\
c_{140}^{\mathrm{A}}=0.00673609579 \\
c_{202}^{A}=0.615185605 \\
c_{211}^{\mathrm{A}}=0.44185333 \\
c_{221}^{\mathrm{A}}=0.62569975 \\
c_{301}^{\mathrm{A}}=0.414265497 \\
c_{311}^{\mathrm{A}}=-0.560754057 \\
c_{401}^{\mathrm{A}}=0.0417331533\end{array}$ \\
\hline
\end{tabular}

TABLE 7: Numerical Values of the Coefficients of Polynomial B in the Three-Body Extended Hartree-Fock Energy in au

\begin{tabular}{|c|c|c|}
\hline $\begin{array}{c}\gamma_{1}^{\mathrm{B}}=0.92 \\
R_{1}^{\mathrm{B}, \mathrm{ref}}=2.80\end{array}$ & $\begin{array}{c}\gamma_{2}^{\mathrm{B}}=0.58 \\
R_{2}^{\mathrm{B}, \mathrm{ref}}=2.68\end{array}$ & $\begin{array}{c}\gamma_{3}^{\mathrm{B}}=0.53 \\
R_{3}^{\mathrm{B}, \text {,ef }}=4.25\end{array}$ \\
\hline $\begin{array}{l}c_{000}^{\mathrm{B}}=0.34268533 \\
c_{003}^{\mathrm{B}}=-0.104628235 \\
c_{010}^{\mathrm{B}}=-0.283879354 \\
c_{013}^{\mathrm{B}}=0.160709558 \\
c_{021}^{\mathrm{B}}=0.00383147459 \\
c_{030}^{\mathrm{B}}=0.755325919 \\
c_{040}^{\mathrm{B}}=0.127078787 \\
c_{100}^{\mathrm{B}}=-0.289964039 \\
c_{103}^{\mathrm{B}}=-0.110590724 \\
c_{111}^{\mathrm{B}}=-0.243992429 \\
c_{120}^{\mathrm{B}}=0.555584386 \\
c_{130}^{\mathrm{B}}=0.360760901 \\
c_{200}^{\mathrm{B}}=-0.756021158 \\
c_{203}^{\mathrm{B}}=-0.097395365 \\
c_{212}^{\mathrm{B}}=-0.20040811 \\
c_{230}^{\mathrm{B}}=-0.0734865405 \\
c_{302}^{\mathrm{B}}=0.0251193461 \\
c_{320}^{\mathrm{B}}=0.0147474065 \\
c_{410}^{\mathrm{B}}=0.0734593641\end{array}$ & $\begin{array}{l}c_{001}^{\mathrm{B}}=-0.156266035 \\
c_{004}^{\mathrm{B}}=-0.0395350302 \\
c_{011}^{\mathrm{B}}=0.0249695419 \\
c_{014}^{\mathrm{B}}=-0.0491731653 \\
c_{022}^{\mathrm{B}}=-0.152090755 \\
c_{031}^{\mathrm{B}}=0.408332247 \\
c_{041}^{\mathrm{B}}=-0.0975231701 \\
c_{101}^{\mathrm{B}}=-0.230472236 \\
c_{104}^{\mathrm{B}}=-0.0994307523 \\
c_{112}^{\mathrm{B}}=0.0311063194 \\
c_{12}^{\mathrm{B}}=-0.370295745 \\
c_{131}^{\mathrm{B}}=0.170133025 \\
c_{201}^{\mathrm{B}}=-0.0522933035 \\
c_{210}^{\mathrm{B}}=0.645931587 \\
c_{220}^{\mathrm{B}}=0.353531971 \\
c_{300}^{\mathrm{B}}=-0.60602039 \\
c_{310}^{\mathrm{B}}=-0.051336385 \\
c_{400}^{\mathrm{B}}=-0.0116238618 \\
c_{500}^{\mathrm{B}}=0.0775702596\end{array}$ & $\begin{array}{l}c_{002}^{\mathrm{B}}=-0.294456751 \\
c_{005}^{\mathrm{B}}=-0.0258194682 \\
c_{012}^{\mathrm{B}}=-0.399127497 \\
c_{020}^{\mathrm{B}}=-0.873890432 \\
c_{023}^{\mathrm{B}}=-0.0320679312 \\
c_{032}^{\mathrm{B}}=0.0708306864 \\
c_{050}^{\mathrm{B}}=-0.114607354 \\
c_{102}^{\mathrm{B}}=0.0972749497 \\
c_{110}^{\mathrm{B}}=-0.550630406 \\
c_{113}^{\mathrm{B}}=-0.198198673 \\
c_{122}^{\mathrm{B}}=0.0569126419 \\
c_{140}^{\mathrm{B}}=-0.157920036 \\
c_{202}^{\mathrm{B}}=-0.0476056622 \\
c_{211}^{\mathrm{B}}=0.280831417 \\
c_{221}^{\mathrm{B}}=0.0319832695 \\
c_{301}^{\mathrm{B}}=0.020614987 \\
c_{311}^{\mathrm{B}}=0.119990554 \\
c_{401}^{\mathrm{B}}=0.205238381\end{array}$ \\
\hline
\end{tabular}

atomic quadrupole adiabatically adjusts its angular orientation to that of the diatomic molecule to give the lowest interaction energy.

The analytical expression for the $\mathrm{OH}$ and $\mathrm{SH}$ dipoles have been obtained by fitting our own ab initio results to the form ${ }^{55}$

$$
\mu(R)=D_{\mathrm{M}}\left(1+\sum_{i=1}^{3} a_{i} r^{i}\right) \exp \left(-\sum_{i=1}^{3} b_{i} r^{i}\right)
$$

where $r=R-R_{\mathrm{M}}$ is the displacement relative to the maximum in $\mu(R)$ and $b_{1} \equiv a_{1}$. In turn, the analytical expression for the intramolecular dependence of the quadrupoles has been chosen to be that previously employed by one of the authors and Rodrigues $^{56}$

$$
Q(R)=D_{\mathrm{M}}\left(1+\sum_{i=1}^{3} a_{i} r^{i}\right) \exp \left(-\sum_{i=1}^{3} b_{i} r^{i}\right)+Q_{\infty}+\chi_{8}(R) \frac{M_{6}}{R^{6}}
$$

where $r=R-R_{\mathrm{M}}$ now in the displacement relative to the maximum in $Q(r)$. The input data for the permanent electric moments has been obtained from ab initio MRCI calculations carried out in the present work. The numerical values of the parameters for the dipole and quadrupole moments using the above equations are given in Tables 4 and 5, while the graphical representation of the dipole and quadrupole as a function of the diatomic bond distance is depicted in Figures 4 and 5 .

3.2.3. Three-Body Extended Hartree-Fock Energy. By subtracting, for a given triatomic geometry, the sum of the twobody energy terms from the corresponding DMBE-SEC interaction energies (defined with respect to the infinitely separated ground-state atoms), one obtains the total three-body energy. Then, by subtracting the three-body electrostatic and dynamical correlation contributions from the total three-body energy calculated above, one gets the remaining three-body extended Hartree-Fock energy contribution. This is represented by using the form 
TABLE 8: Numerical Values of the Coefficients of Polynomial $C$ in the Three-Body Extended Hartree-Fock Energy in au

\begin{tabular}{|c|c|c|}
\hline $\begin{array}{c}\gamma_{1}^{\mathrm{C}}=0.76 \\
R_{1}^{\mathrm{C}, \text { ref }}=3.35\end{array}$ & $\begin{array}{c}\gamma_{2}^{C}=0.61 \\
R_{2}^{C, \text { ref }}=3.00\end{array}$ & $\begin{array}{c}\gamma_{3}^{C}=0.50 \\
R_{3}^{C, \text { ref }}=3.04\end{array}$ \\
\hline$c_{000}^{c}=-0.0368229496$ & $c_{001}^{c}=-0.129003395$ & $c_{002}^{c}=0.20818244$ \\
\hline$c_{003}^{c}=-0.215560967$ & $c_{004}^{C}=0.0327436241$ & $c_{005}^{c}=-0.00277579984$ \\
\hline$c_{010}^{c}=-0.344210958$ & $c_{011}^{C^{c t}}=0.31920124$ & $c_{012}^{c}=0.676245148$ \\
\hline$c_{013}^{c}=-0.0588732027$ & $c_{014}^{c 11}=0.0626825399$ & $c_{020}^{c}=-1.01984483$ \\
\hline$c_{021}^{c}=-1.06002701$ & $c_{022}^{c}=-0.285430471$ & $c_{023}^{c}=-0.0121593163$ \\
\hline$c_{030}^{c}=0.0989442215$ & $c_{031}^{c 2}=0.0487608753$ & $c_{032}^{c}=-0.0346353473$ \\
\hline$c_{040}^{C}=0.442210508$ & $c_{041}^{c}=0.0155389963$ & $c_{050}^{c}=0.0192298535$ \\
\hline$c_{100}^{c}=-0.178793571$ & $c_{101}^{c}=-0.647450641$ & $c_{102}^{c}=-0.545972629$ \\
\hline$c_{103}^{C}=0.0671127689$ & $c_{104}^{c}=0.0147832243$ & $c_{110}^{c^{C}}=-0.192412049$ \\
\hline$c_{111}^{c}=0.511735943$ & $c_{112}^{c}=-0.0906728726$ & $c_{113}^{c}=-0.0121194958$ \\
\hline$c_{120}^{C}=-0.283103789$ & $c_{121}^{c}=-0.0710891685$ & $c_{122}^{c}=-0.0971627429$ \\
\hline$c_{130}^{c}=0.167061534$ & $c_{131}=-0.135636288$ & $c_{140}^{c}=-0.150887754$ \\
\hline$c_{200}^{c}=-0.0535259653$ & $c_{201}^{c^{c}}=-0.699043015$ & $c_{202}^{c}=-0.0428548027$ \\
\hline$c_{203}^{c}=0.0128170641$ & $c_{210}^{c}=-0.680231297$ & $c_{211}^{c}=0.188599247$ \\
\hline$c_{212}^{\bar{c}}=-0.0217923261$ & $c_{220}^{c}=0.507919222$ & $c_{221}^{c}=-0.0884283396$ \\
\hline$c_{230}^{c}=-0.0990154673$ & $c_{300}^{c^{20}}=0.392368471$ & $c_{301}^{c 1}=-0.614484326$ \\
\hline$c_{302}^{c}=0.0507822473$ & $c_{310}^{c}=0.5668414$ & $c_{311}^{c}=0.121341497$ \\
\hline$c_{320}^{c}=-0.117210525$ & $c_{400}^{c}=-0.445262241$ & $c_{401}^{c}=0.0612374732$ \\
\hline$c_{410}^{c^{c}}=-0.107519532$ & $c_{500}^{c}=0.0639223458$ & \\
\hline
\end{tabular}

$$
\begin{aligned}
& V_{\mathrm{EHF}}^{(3)}=\sum_{\mathrm{K}=\mathrm{A}, \mathrm{B}, \mathrm{C}}\left(\sum_{i=0}^{N_{\mathrm{K}}}, \sum_{j=0}^{N_{\mathrm{K}}}, \sum_{k=0}^{N_{K}}{ }^{\prime} c_{i j k}^{\mathrm{K}} Q_{1}^{i} Q_{2}^{j} Q_{3}^{k}\right) \prod_{i=1}^{3}\{1- \\
& \left.\tanh \left[\gamma_{i}^{\mathrm{K}}\left(R_{i}-R_{i}^{\mathrm{K}, \mathrm{ref}}\right)\right]\right\}
\end{aligned}
$$

where $N_{\mathrm{A}}=N_{\mathrm{B}}=N_{\mathrm{C}}=5$, the prime means that the sum is restricted to $i+j+k \leq 5$, and the symmetry coordinates are defined as

$$
\left(\begin{array}{l}
Q_{1} \\
Q_{2} \\
Q_{3}
\end{array}\right)=\left(\begin{array}{ccc}
\sqrt{\frac{1}{3}} & \sqrt{\frac{1}{3}} & \sqrt{\frac{1}{3}} \\
0 & \sqrt{\frac{1}{2}} & -\sqrt{\frac{1}{2}} \\
\sqrt{\frac{2}{6}} & -\sqrt{\frac{1}{6}} & -\sqrt{\frac{1}{6}}
\end{array}\right)\left(\begin{array}{l}
R_{1}-R_{1}^{\mathrm{K}, \mathrm{ref}} \\
R_{2}-R_{2}^{\mathrm{K}, \mathrm{ref}} \\
R_{3}-R_{3}^{\mathrm{K}, \mathrm{ref}}
\end{array}\right)
$$

The complete set of parameters (186 in all) is $56 c_{i j k}, 3 \gamma_{i}$, and $3 R_{i}^{\text {ref }}$, for each polynomial (A , B , or C) in eq 24 , having been obtained from a fit of the complete potential energy surface to our DMBE-SEC energies. Three polynomials of the same type and size (A, B , or C in eq 24) have been employed, one at each of the following stationary points: HSO, HOS, and HSO $\rightarrow$ HOS isomerization transition state (in that order). Thus, the origin of the displacement coordinates is for each polynomial taken to be close to the geometry of the corresponding stationary point. Figure 6 shows the reference geometries (broken lines) employed for the three polynomials in comparison with the geometries of HSO, HOS, and isomerization saddle point predicted by the DMBE potential energy surface (solid line). To obtain $R_{i}^{\mathrm{K} \text {,ref }}$, we have first assumed their values to be the equilibrium geometries and, subsequently, optimized them through a trial-and-error procedure by carrying out linear leastsquares fits. The $\gamma_{i}$ values have also been optimized in a similar way. The points included in the fits have been chosen with the condition that the total energy does not exceed $300 \mathrm{kcal} \mathrm{mol}^{-1}$ with respect to the HSO minimum. This procedure reduced the number of fitted points to 461. The numerical values of the parameters obtained from such a procedure are listed in Tables 6-8.

Table 9 shows the stratified root-mean-squared deviations (rmsd) of the final fit with respect to the fitted and nonfitted
TABLE 9: Stratified Root-mean-square Deviations (in kcal $\mathrm{mol}^{-1}$ ) of the DMBE Potential Energy Surface

\begin{tabular}{ccc}
\hline$E /\left(\mathrm{kcal} \mathrm{mol}^{-1}\right)$ & $N$ & $\mathrm{rms}^{a}$ \\
\hline 5 & 20 & 0.654 \\
10 & 53 & 0.723 \\
20 & 66 & 0.692 \\
30 & 73 & 0.790 \\
40 & 85 & 0.822 \\
50 & 107 & 0.866 \\
60 & 129 & 0.853 \\
70 & 198 & 0.841 \\
80 & 230 & 0.849 \\
90 & 261 & 0.910 \\
100 & 309 & 0.987 \\
110 & 348 & 0.997 \\
120 & 369 & 1.040 \\
130 & 397 & 1.051 \\
140 & 404 & 1.053 \\
150 & 410 & 1.064 \\
160 & 418 & 1.060 \\
170 & 430 & 1.058 \\
180 & 443 & 1.075 \\
200 & 453 & 1.076 \\
300 & 461 & 1.069 \\
400 & 466 & 1.553 \\
500 & 477 & 2.793
\end{tabular}

${ }^{a}$ The values in italic imply that the points above the energy quoted in the first column have not been included in the fit.

$\mathrm{ab}$ initio energies. As seen from Table 9, the final potential energy surface is able to fit 461 points (with energies up to $300 \mathrm{kcal} \mathrm{mol}^{-1}$ ) with an accuracy of ca. $1 \mathrm{kcal} \mathrm{mol}^{-1}$. Also seen from Table 9 is the fact that the nonfitted points are well reproduced by the DMBE potential energy surface of the present work; the rmsd is $2.8 \mathrm{kcal} \mathrm{mol}^{-1}$ for all points below $500 \mathrm{kcal}$ $\mathrm{mol}^{-1}$.

\section{Features of the Potential Energy Surface}

The DMBE potential energy surface predicts the most stable minimum to be that associated with the HSO conformer. In fact, as seen from Table 10, HSO is $0.9 \mathrm{kcal} \mathrm{mol}^{-1}$ lower in energy than HOS. This result conforms with the most accurate theoretical predictions of Goumri et al., ${ }^{7}$ who have predicted from their G-2 calculations an energy difference of $2.1 \mathrm{kcal}$ 
TABLE 10: Stationary Points of the DMBE Potential Energy Surface ${ }^{a}$

\begin{tabular}{|c|c|c|c|c|c|c|c|}
\hline & $R_{\mathrm{OH}} / a_{0}$ & $R_{\mathrm{SH}} / a_{0}$ & $R_{\mathrm{SO}} / a_{0}$ & $E / \mathrm{kcal} \mathrm{mol}^{-1}$ & $\omega_{1}$ & $\omega_{2}$ & $\omega_{3}$ \\
\hline HSO & $\begin{array}{c}4.4857 \\
(4.3697)^{c} \\
(4.2502)^{d}\end{array}$ & $\begin{array}{c}2.6190 \\
(2.6248)^{c} \\
(2.5511)^{d}\end{array}$ & $\begin{array}{c}2.8569 \\
(2.8233)^{c} \\
(2.9102)^{d}\end{array}$ & $0.0^{b}$ & $\begin{array}{c}998 \\
(1026)^{c} \\
(1013)^{d}\end{array}$ & $\begin{array}{l}1054 \\
(1164)^{c} \\
(1063)^{d}\end{array}$ & $\begin{array}{l}2181 \\
(2271)^{c} \\
(2570)^{d}\end{array}$ \\
\hline HOS & 1.8233 & 4.0819 & 3.0983 & $\begin{array}{l}0.9^{b} \\
2.1^{e}\end{array}$ & 839 & 1080 & 3783 \\
\hline $\begin{array}{l}S \cdots H O \\
S H \cdots \cdot O\end{array}$ & $\begin{array}{l}1.8360 \\
5.4670\end{array}$ & $\begin{array}{r}5.2513 \\
25142\end{array}$ & $\begin{array}{l}7.0873 \\
7.9812\end{array}$ & $\begin{array}{l}-3.3^{f} \\
-14^{g}\end{array}$ & $\begin{array}{r}118 \\
80\end{array}$ & $\begin{array}{l}215 \\
104\end{array}$ & $\begin{array}{l}3739 \\
2802\end{array}$ \\
\hline TS1 & 2.5679 & 2.7084 & 3.1668 & $\begin{array}{l}46.7^{b} \\
47.6^{e}\end{array}$ & $1711 \mathrm{i}$ & 744 & 2354 \\
\hline TS2 & 4.0509 & 6.0086 & 2.8296 & $\begin{array}{l}1.7^{h} \\
1.8^{i}\end{array}$ & $392 \mathrm{i}$ & 291 & 1047 \\
\hline $\begin{array}{l}\text { TS3 } \\
\text { TS4 }\end{array}$ & $\begin{array}{l}7.1363 \\
18379\end{array}$ & $\begin{array}{l}2.5335 \\
5.4132\end{array}$ & 6.3778 & $1.1^{j}$ & $\begin{array}{r}97 i \\
139 i\end{array}$ & 151 & $\begin{array}{l}2725 \\
3758\end{array}$ \\
\hline
\end{tabular}

${ }^{a}$ Harmonic frequencies are in $\mathrm{cm}^{-1}$, and the experimental values are in parentheses when available. ${ }^{b}$ Relative to the absolute minimum of $\mathrm{HSO}$, $-0.29615726 E_{\mathrm{h}} \cdot{ }^{c}$ Experimental values from ref $16 .{ }^{d}$ Experimental values from ref $11 .{ }^{e}$ Best theoretical estimate, ref $7 .{ }^{f}$ Relative to the energy of $\mathrm{S}+\mathrm{OH}$ channel, $-0.17020 E_{\mathrm{h}} \cdot{ }^{g}$ Relative to the energy of O $+\mathrm{SH}$ channel, $-0.13921 E_{\mathrm{h}} \cdot{ }^{h}$ Relative to the energy of H $+\mathrm{SO}$ channel, $-0.19901 E_{\mathrm{h}}$. ${ }^{i}$ Best theoretical estimate, ref. 27. ${ }^{j}$ Relative to the minimum SH $\cdots$ O. ${ }^{k}$ Relative to the minimum S $\cdots \mathrm{HO}$.

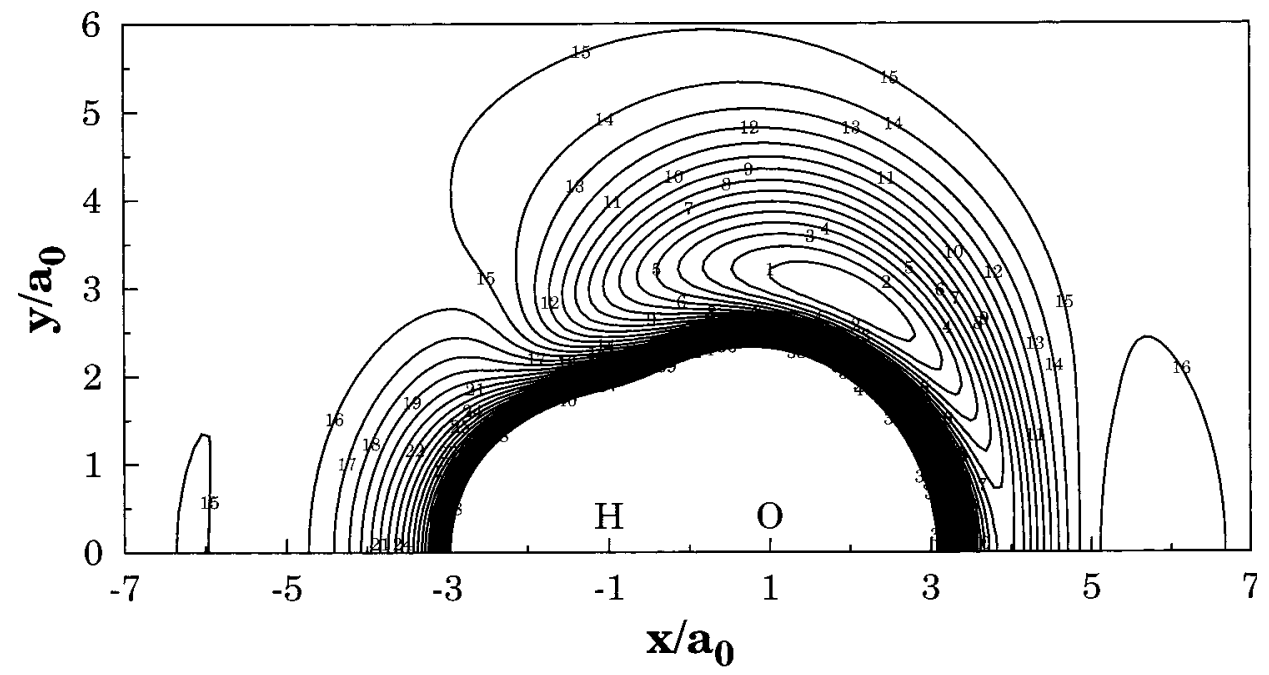

Figure 7. Contour plot for a $\mathrm{S}$ atom moving around the equilibrium $\mathrm{OH}$ molecule. Contours start at $-0.287 E_{\mathrm{h}}$, with successive contours at intervals of $-0.008 E_{\mathrm{h}}$.

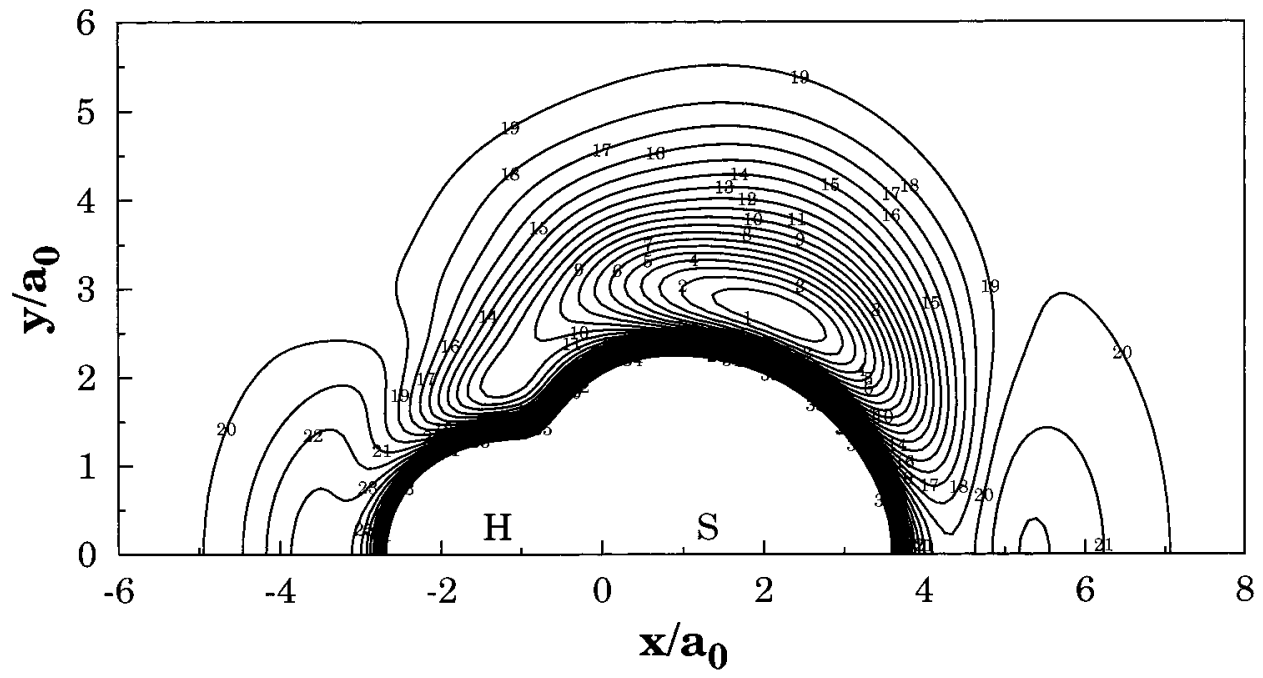

Figure 8. Contour plot for a $\mathrm{O}$ atom moving around the equilibrium $\mathrm{SH}$ molecule. Contours start at $-0.287 E_{\mathrm{h}}$, with successive contours at intervals of $-0.008 E_{\mathrm{h}}$.

$\mathrm{mol}^{-1}$. We have also found two van der Waals minima, namely $\mathrm{S} \cdots \mathrm{HO}$ and $\mathrm{SH} \cdots \mathrm{O}$, which lie 3.3 and $1.4 \mathrm{kcal} \mathrm{mol}^{-1}$ below the corresponding dissociation channels $(\mathrm{S}+\mathrm{OH}$ or $\mathrm{SH}+\mathrm{O})$, respectively.
In Table 10, we report also four saddle points of index one. The first, labeled TS1, connects the two isomers HSO and HOS and is located $46.7 \mathrm{kcal} \mathrm{mol}^{-1}$ above the global minimum. Such an estimate agrees within $0.9 \mathrm{kcal} \mathrm{mol}^{-1}$ with the ab initio results 


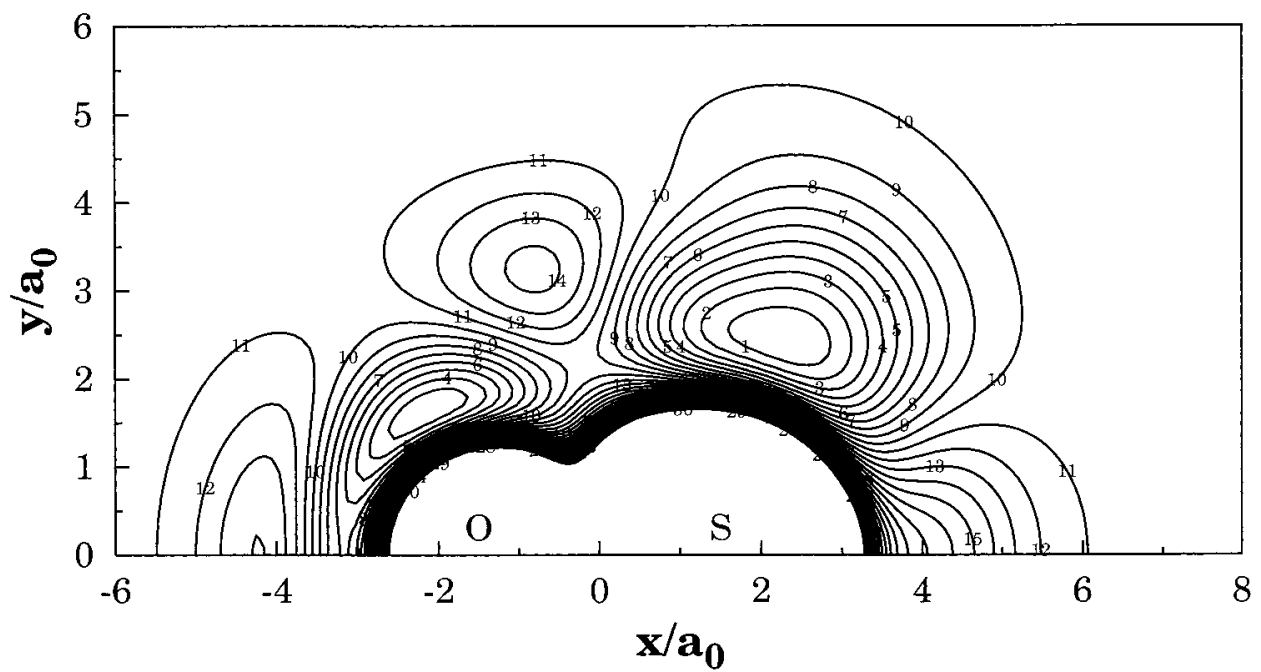

Figure 9. Contour plot for a $\mathrm{H}$ atom moving around the equilibrium $\mathrm{SO}$ molecule. Contours start at $-0.287 E_{\mathrm{h}}$, with successive contours at intervals of $-0.009 \mathrm{E}_{\mathrm{h}}$

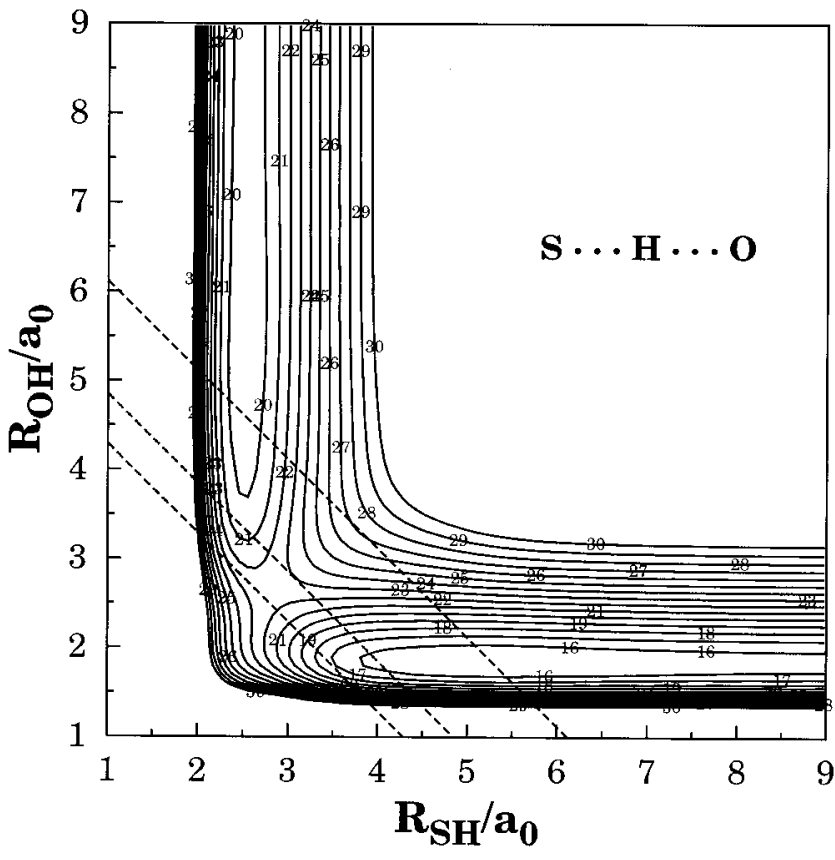

Figure 10. Stretching contour plot for linear $\mathrm{S}-\mathrm{H}-\mathrm{O}$. Contours start at $-0.287 E_{\mathrm{h}}$, with successive contours at intervals of $-0.008 E_{\mathrm{h}}$. The dashed straight lines indicate the cuts associated with the curves shown in Figure 11.

of Goumri et al. ${ }^{7}$ and $0.1 \mathrm{kcal} \mathrm{mol}^{-1}$ with those of Xantheas and Dunning. ${ }^{27}$ These authors suggested that such a large barrier might explain why only the isomer HSO is observed experimentally. The experimental geometry and frequencies of HSO are also included in Table 10 for comparison. The saddle point TS2 corresponds to a small barrier for the dissociation process $\mathrm{HSO} \rightarrow \mathrm{H}+\mathrm{SO}$ and is located $1.5 \mathrm{kcal} \mathrm{mol}^{-1}$ above the dissociation limit; a value very similar to this one has also been obtained by Xantheas and Dunning ${ }^{27}$ in their ab initio calculations $\left(1.8 \mathrm{kcal} \mathrm{mol}^{-1}\right)$. In addition, the saddle points TS3 and TS4 have been found to connect the HSO or HOS isomers with the two van der Waals minima. Such stationary points lie 1.1 and $3.3 \mathrm{kcal} \mathrm{mol}^{-1}$ above the corresponding van der Waals minima.

Figure 7 shows a contour plot for a S atom moving around an equilibrium $\mathrm{OH}$ molecule. The main feature in this Figure is the HOS minimum. Also visible is a saddle point of index two which occurs for linear geometries.
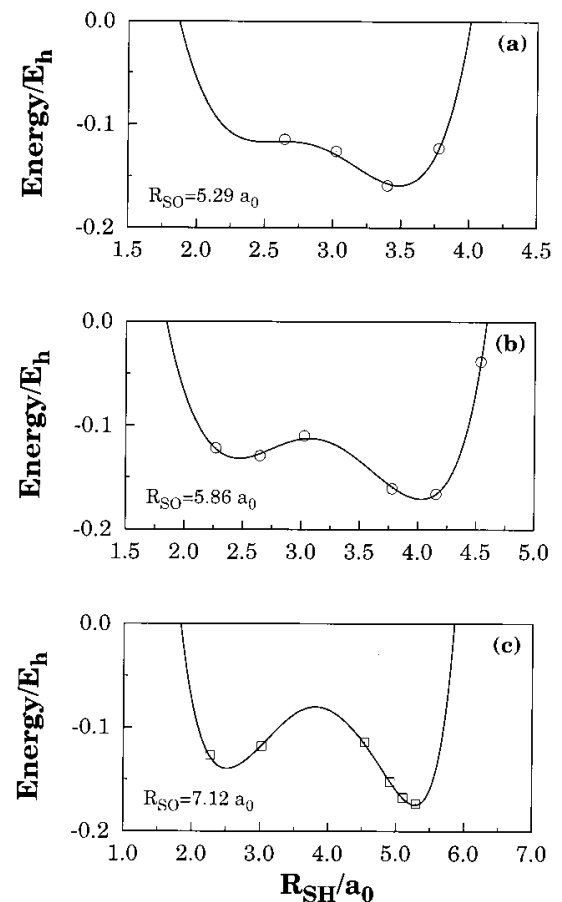

Figure 11. Potential energy curves for $\mathrm{S}-\mathrm{H}-\mathrm{O}$ linear configurations at fixed SO distances of (a) 5.29, (b) 5.86, and (c) $7.12 a_{0}$. Also shown for comparison are the DMBE-SEC points of the present work: $(\mathrm{O})$ points included in the fit; $(\triangle)$ points not included in the fit. See also Figure 10.

In Figure 8, we show a contour plot for an $\mathrm{O}$ atom moving around an equilibrium $\mathrm{SH}$ molecule. The notable features in this plot are the HSO minimum and a saddle point of index two for linear geometries. In addition, there is a stationary point at high energies which appears as a minimum in the twodimensional (2D) space scanned in the plot. Indeed, it corresponds in $3 \mathrm{D}$ to the isomerization transition state for the reaction $\mathrm{HSO} \rightarrow$ HOS.

The plot for a $\mathrm{H}$ atom moving around an equilibrium $\mathrm{SO}$ molecule is shown in Figure 9. In this case, the minima associated with both isomers become clearly visible, as well as the isomerization transition state (TS1) connecting them. Not visible in the plot though is the transition state (TS2) for the $\mathrm{H}$-atom dissociation process $\mathrm{HOS} \rightarrow \mathrm{H}+\mathrm{OS}$. Another important feature from this plot arises as a saddle point of index 

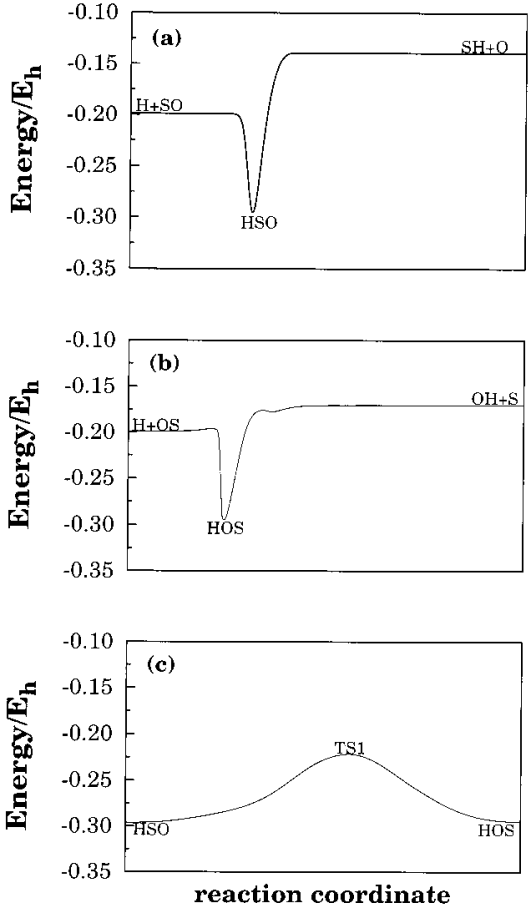

Figure 12. Minimum energy path for the reactions involving the (a) HSO isomer, (b) HOS, and (c) both.

two at the center of the plot. Looking like a maximum (apparently due to an avoided crossing), such a feature should trully be a cusp originated from the crossing of the two lowest electronic states.

Figure 10 shows a contour plot for linear $\mathrm{S}-\mathrm{H}-\mathrm{O}$ stretching. The main feature from this plot is the $\mathrm{OH} \cdots \mathrm{S}$ van der Waals minimum and a saddle point of index two connecting this minimum with the $\mathrm{SH} \cdots \mathrm{O}$ one, also visible in the figure. Also indicated by the dashed lines in this contour plot are cuts corresponding to the curves shown in Figure 11. These are depicted mainly to show that the agreement with the ab initio data is good, and hence, our predicted attributes for the $\mathrm{OH} \cdots \mathrm{S}$ hydrogen-bonded minimum should be reliable. In fact, as a test of our DMBE potential energy surface, and in order to verify the reliability of the hydrogen bonded structure $\mathrm{OH} \cdots \mathrm{S}$, we have calculated additional (nonfitted) ab initio points at a fixed SO distance of $7.12 a_{0}$. These points are displayed graphically in Figure 11c as a function of the $\mathrm{SH}$ distance with special symbols. Also shown in this Figure is the prediction of our DMBE potential surface. Clearly, the agreement between our fitted surface and the calculated points is quite satisfactory, suggesting that the $\mathrm{OH} \cdots$ S hydrogen-bond structure is reliably described.

Figure 12 shows the minimum energy paths for the reactions $\mathrm{H}+\mathrm{SO} \rightarrow \mathrm{HS}+\mathrm{O}$ and $\mathrm{H}+\mathrm{SO} \rightarrow \mathrm{HO}+\mathrm{S}$. Specifically, Figure $12 \mathrm{a}$ shows the minimum-energy path for the reaction $\mathrm{H}$ $+\mathrm{SO} \rightarrow \mathrm{SH}+\mathrm{O}$, which involves the global HSO minimum. As seen from this figure, there is no barrier for the dissociation process $\mathrm{HSO} \rightarrow \mathrm{H}+\mathrm{SO}$. In addition, the $\mathrm{HSO} \rightarrow \mathrm{SH}+\mathrm{O}$ channel shows no barrier to dissociation either.

The minimum energy path for the process $\mathrm{H}+\mathrm{OS} \rightarrow \mathrm{OH}+$ $\mathrm{S}$ is shown in Figure 12b. Clearly, the relevant isomer is now HOS. Note that the HOS $\rightarrow \mathrm{H}+\mathrm{OS}$ dissociation process has a barrier (TS2), which is about $1.7 \mathrm{kcal} \mathrm{mol}^{-1}$ above the $\mathrm{H}+$ $\mathrm{OS}$ channel. In turn, the channel leading to $\mathrm{OH}+\mathrm{S}$ has no barrier.

We have also computed the minimum energy path for the isomerization process $\mathrm{HSO} \rightarrow \mathrm{HOS}$, which is shown in Figure

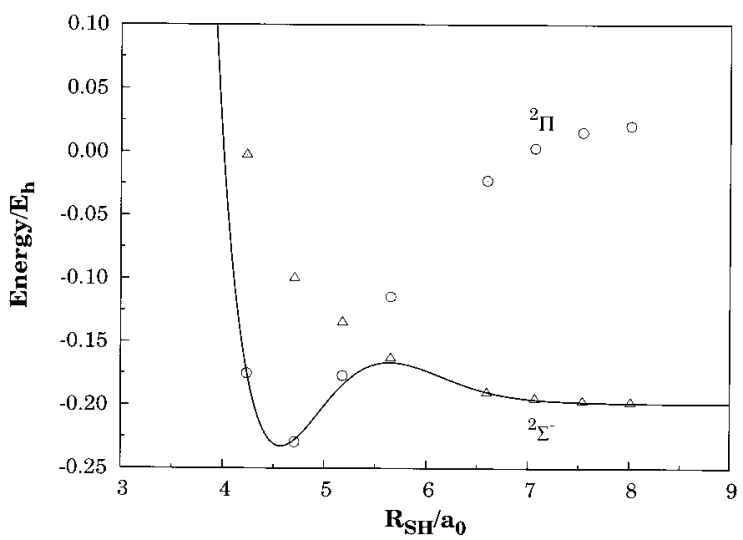

Figure 13. DMBE-SEC points for the ${ }^{2} \Sigma^{-}(\triangle)$ and ${ }^{2} \Pi(O)$ states as a function of the HS bond distance. Also shown is the prediction of our DMBE potential energy surface.

12c. Clearly, the two isomers (HSO and HOS) are connected by a saddle point of index 1 (TS1) located $46.6 \mathrm{kcal} \mathrm{mol}^{-1}$ above the HSO minimum.

Finally, we comment on the fact that our ab initio calculations predict a ${ }^{2} \Sigma^{-} / 2 \Pi$ crossing along the path for $\mathrm{H}$ approaching collinearly OS. Such a crossing is dictated by symmetry arguments, and hence becomes an avoided crossing at less symmetrical geometries $\left(C_{s}\right)$. This is illustrated in Figure 13, which shows our DMBE-SEC points for the ${ }^{2} \Sigma^{-}$and ${ }^{2} \Pi$ states as a function of the HS bond distance. Also shown in this figure is the prediction of our fitted DMBE single-valued potential energy surface. We observe that the fit is good but displays by built-in construction a smoothed maximum at regions where the crossing should take place.

\section{Conclusions}

We have reported a global single-valued DMBE form for the ground electronic state of HSO. This function has been calibrated from novel MR CISD ab initio energies after being corrected for the complete one-electron basis set/complete CI limit. This has been done using the DMBE-SEC method described elsewhere. ${ }^{29}$ To improve the accuracy of the fit, we have introduced an $n$-body distributed polynomial approach, which implies using an individual multinomial development at the various stationary points. For simplicity, these have been restricted to the three most relevant ones corresponding to two minima (HSO, HOS) and the saddle point connecting them.

Acknowledgment. This work has been supported by the Fundação para a Ciência e Tecnologia, Portugal, under program PRAXIS XXI.

\section{References and Notes}

(1) Cuppit, L. T.; Gless, G. P. Trans. Faraday Soc. 1970, 66, 3007.

(2) Hollinden, G. A.; Kurylo, M. J.; Timmons, R. B. J. Phys. Chem 1970, $74,988$.

(3) Takahashi, S. Mem. Nat. Def. Acad. Jpn. 1970, 10, 369.

(4) Whytock, D. A.; Timmons, R. B.; Lee, J. H.; Michael, J. V. J. Chem. Phys. 1976, 65, 2052. 1333.

(5) Slagle, I. R.; Baiochi, F.; Gutman, D. J. Phys. Chem. 1978, 82,

(6) Singleton, D. L.; Irwin, R. S.; Nip, W. S.; Cvetanovic, R. J. J. Phys. Chem. 1979, 83, 2195.

(7) Goumri, A.; Laakso, D.; Rocha, J.-D. R.; Smith, C. E.; Marshall, P. J. Chem. Phys. 1995, 102, 161.

(8) Black, G. J. J. Chem. Phys. 1984, 80, 1103.

(9) Friedl, R. R.; Brune, W. H.; Anderson, J. G. J. Phys. Chem. 1985 , 89, 5505. 483. 
(11) Schurath, U.; Weber, M.; Becker, K. H. J. Chem. Phys. 1977, 67, 110.

(12) Benson, S. W. Chem. Rev. 1978, 78, 23.

(13) Hinchliffe, A. J. Mol. Struct. 1980, 66, 235.

(14) De, B. R.; Sannigrahi, A. B. J. Comput. Chem. 1980, 1, 334.

(15) Kamimoto, M.; Saito, S.; Hirota, E. J. Mol. Spectrosc. 1980, 84, 334.

(16) Ohashi, N.; Kamimoto, M.; Saito, S.; Hirota, E. J. Mol. Spectrosc. 1980, 84, 204

(17) Sears, T. J.; McKellar, A. R. W. Mol. Phys. 1983, 49, 25.

(18) Luke, B. T.; McLean, A. D. J. Phys. Chem. 1985, 89, 4592.

(19) Plummer, P. L. J. Chem. Phys. 1990, 92, 6627.

(20) O'Hair, R. A. J.; DePuy, C. H.; Bierbaum, V. M. J. Phys. Chem. 1993, 97, 7955

(21) Chang, Y.-T.; Loew, G. H. Chem. Phys. Lett. 1993, 205, 543.

(22) Espinosa-Garcia, J.; Corchado, J. C. Chem. Phys. Lett. 1994, 218 128 .

(23) Iraqui, M.; Golberg, N.; Schwarz, H. J. Phys. Chem. 1994, 98, 2015.

(24) Morris, V. R.; Jackson, W. M. Chem. Phys. Lett. 1994, 223, 445.

(25) Essefar, M.; Mó, O.; Yañez, M. J. Chem. Phys. 1994, 101, 2175.

(26) Sannigrahi, A. B.; Thunemmann, K. H.; Peyerimhoff, S. D.; Buenker, R. J. Chem. Phys. 1977, 20, 25.

(27) Xantheas, S. S.; Dunning, T. H., Jr. J. Phys. Chem. 1993, 97, 6616

(28) Denis, P. A.; Ventura, O. N. Int. J. Quantum Chem. 2000, 80, 439.

(29) Varandas, A. J. C. J. Chem. Phys. 1989, 90, 4379.

(30) Varandas, A. J. C. THEOCHEM 1985, 120, 401.

(31) Varandas, A. J. C. Adv. Chem. Phys. 1988, 74, 255

(32) Varandas, A. J. C. Chem. Phys. Lett. 1992, 194, 333.

(33) Varandas, A. J. C. In Dynamical Processes in Molecular Physics Delgado-Barrio, G., Ed.; IOP Publishing: Bristol, U.K., 1993; p 3.

(34) Varandas, A. J. C In Reaction and Molecular Dynamics; Lagana, A., Riganelli, A., Eds.; Springer, Berlin, 20001 Vol. 75 of Lecture Notes in Chemistry, p 33.

(35) Werner, H.-J.; Knowles, P. J. J. Chem. Phys. 1988, 89, 5803.
(36) Werner, H.-J.; Knowles, P. J. J. Chem. Phys. 1985, 82, 5053.

(37) Knowles, P. J.; Werner, H.-J. Chem. Phys. Lett. 1985, 115, 259.

(38) Dunning, T. H., Jr. J. Chem. Phys. 1989, 90, 1007.

(39) Kendall, R.; Dunning, T. H., Jr.; Harrison, R. J. Chem. Phys. 1992, 96,6769 .

(40) Woon, D.; Dunning, T. H., Jr. J. Chem. Phys. 1993, 98, 1358.

(41) Werner, H.-J.; Knowles, P. J. MOLPRO is a package of ab initio programs written by H.-J. Werner and P. J. Knowles, with contributions from J. Almlöf, R D. Amos, M. J. O. Deegan, S. T. Elbert, C. Hampel, W. Meyer, K. A. Peterson, R. Pitzer, A. J. Stone, P. R Taylor, and R. Lindh, 1998.

(42) Varandas, A. J. C.; Silva, J. D. J. Chem. Soc., Faraday Trans. 1992, 88,941

(43) Varandas, A. J. C. Mol. Phys. 1987, 60, 527.

(44) Roy, R. J. L. Spec. Period. Rep. Chem. Soc. Mol. Spectrosc. 1973 1,113 .

(45) Varandas, A. J. C.; Voronin, A. I. Chem. Phys. 1995, 194, 91.

(46) Wilson, S. H. S.; Hove, J. D.; Ashfold, M. N. R. Mol. Phys. 1996 88,841

(47) Singh, A. N.; Rai, D. K. J. Chem. Phys. 1965, 43, 2151.

(48) Clerbaux, G.; Colin, R. J. Mol. Struct. 1994, 165, 334.

(49) Varandas, A. J. C. J. Chem. Phys. 1996, 105, 3524

(50) Varandas, A. J. C.; Rodrigues, S. P. J. Chem. Phys. Lett. 1995, 245,66

(51) Matias, M. A.; Varandas, A. J. C. Mol. Phys. 1990, 70, 623

(52) Buckingham, A. D. Adv. Chem. Phys. 1967, 12, 107.

(53) Varandas, A. J. C.; Rodrigues, S. P. J. J. Chem. Phys. 1997, 106 9647.

(54) Varandas, A. J. C. THEOCHEM 1988, 166, 59

(55) Varandas, A. J. C. In Conferencias Plenarias de la XXIII Reunión Bienal de Química; Feliciano, A. S., Grande, M., Casado, J., Eds.; Universidad de Salamanca: Salamanca, Spain, 1991; p 321.

(56) Rodrigues, S. P. J.; Varandas, A. J. C. Phys. Chem. Chem. Phys. 2000, 2, 435 . 